\title{
Big Bang technology: What's next in design education, radical innovation or incremental change?
}

\author{
Katja Fleischmann \\ School of Creative Arts \\ James Cook University, Australia \\ katja.fleischmann@jcu.edu.au
}

\begin{abstract}
Since the introduction of digital media, design education has been challenged by the ongoing advancement of technology. Technological change has created unprecedented possibilities for designers to engage in the broadening realm of interactive digital media. The increasing sophistication of interactivity has brought a complexity which needs to be managed; most notably, information technology. The mobile device revolution has changed people's lives and created distinct challenges for design educators to master. Social media provide new possibilities as/for teaching technologies to engage students. On the downside, designers compete with amateurs through crowdsourcing platforms. Responses to manage the rapid technological advance in design education have emerged as pockets of innovation from some institutions. This paper takes a closer look at how technology has affected and continues to affect design education in the context of design educators and practitioners arguing that design education is stuck in the past. Does every technological "revolution" require a radical change in design education? To answer this question the broadening and squeezing of design education is examined in the context of the increasing complexity of technology. Potential and "must have" responses to technological challenges are illustrated through examples from an undergraduate digital media design major.
\end{abstract}

\section{Keywords}

digital media design, curriculum design, multidisciplinary collaboration, social media

\section{Introduction}

Design education programs such as Graphic Design and Communication Design had, until the 1980s, clear directions and a similar purpose (Davis, 1998). It was accepted that "graphic design curricula shared many of the same tools, production standards, and methodologies as many other studio-oriented courses" (Panning, 2005, p.15). Programs were print-focused, educating students to the design media that dominated society at the time; namely, print news, magazines, books and other printed material. Designers and design educators "were secure in the scope of their business; the body of knowledge necessary to practice graphic design was known" (Davis, 1998, p. 25). Although the introduction of the Macintosh computer in 1984 changed the graphic design profession forever and in revolutionary ways, through shifting the creation and production process from analogue to digital, it was in retrospect only a change of tools. Instead of using marker comps, T-squares and paste-ups (analogue tools) to create a magazine layout, a computer with 
design software (digital tools) was used to design the "same" layout.

The emergence of digital media, however, brought a paradigm shift requiring new ways of thinking and the development of new design knowledge and skills. Digital media are usually produced for screen-based environments such as a computer, video or touch screen. Mouse, pen, direct touch and even voice or body movements are used for creating a dialogue between a human being (the user) and the application, turning a usually passive audience observer into an audience in control of dynamic content (Flew, 2008). It is this central concept of interactivity that distinguishes digital media (Flew, 2008) from both analogue media (e.g. a printed newspaper) and digitised media (e.g. a scanned photograph) and represents "one of the most striking advances, compared to traditional media" (McEntaggart, 2010). As technologies developed rapidly affecting the way society consumed content, design education needed to embrace this shift and change. It is evident that the rapid technological advance of digital media poses vast challenges for design education, especially considering universities" "inimical relation to the speed of technological and social change" (Gromala, 2001, p. 50). In the early part of the $21^{\text {st }}$ century, Fried (2001) described the process of design education adapting to the new directions as difficult, "a struggle to gain access to new technology, a struggle to learn to use it, and a struggle to find its place in the curriculum" (p. 12).

Meanwhile, the mobile device revolution took place, turning mobile devices such as smartphones and tablet computers into "a channel for delivering communication, services and media" (McMillan, 2009, p. 28). This represents a new paradigm with its own set of rules and a design language still to be fully developed (McMillan, 2009) and implemented in digital media design curricula. Augmented Reality (AR) is said to be the "next big thing in tech" (Farber, 2013) with digital media designers a part of designing immersive systems that promise "adding more information to your existing view of [the] world" (Chaurasia, 2013). In the intervening time, social media have once again changed the way people communicate and interact with each other in revolutionary ways. While still considered in its infancy (Caper, 2013), the popularity of social media has already affected the design profession and arguably design education. Thus, technological change has created a design profession in a state of flux. With technological developments and innovations being introduced at a rapid and continuing pace, mind-staggering possibilities and overwhelming challenges often appear to reside next to each other when attempting to change design education. Transformations happen fast; but does each "revolution" require "radical innovation" in design education?

This paper takes a closer look at how technology has affected and continues to affect design education in the context of design educators and practitioners arguing that design education is stuck in the past (e.g. Davis, 2011, Norman, 2011), "out of date" (Dubberly, 2011, p. 81) and seemingly incapable of meeting the demands of the changed scope of the profession (Canniffe, 2011), leading to the questioning and challenging of existing design curricula. Using the Digital Media Design major of the Bachelor of New Media Arts degree in a medium-sized Australian University as an example, this paper questions which technological advancements - recent and not so recent - urgently require an innovative approach to redesigning the existing design curriculum and/or involve incremental change.

\section{Digital media revolution: challenges for design education}

The digital media revolution has not only changed forever the design profession, but also the teaching of design in higher education. According to Barnes-Powell (2008), the "two momentum trends of this century are the growing complexity and increasing rates of change" (p. 378). Rubbo, Brew and Sachs (2007) agree, however, they argue that, in the contemporary complex and ever changing world, "it is impossible to prepare students for a future that is yet to take shape" (p. 187). Indeed, questions raised by design educators since the emergence of digital media are indicative of the challenges design education faces. Table 1 presents a summary of some of the key questions, with authors ordered chronologically in order to explore any change over time. 
Table 1

Key questions presented by contemporary design educators.

\begin{tabular}{ll}
\hline \multicolumn{1}{c}{ Author (Year) } & \multicolumn{1}{c}{ Question(s) } \\
\hline Justice (1998) & $\begin{array}{l}\text { So, what is happening to the traditional design curriculum in light of the } \\
\text { infusion of computers and other technologies? }\end{array}$ \\
Boyarski (1998) & $\begin{array}{l}\text { The challenge for design education is this: how flexible can our } \\
\text { educational structures be in order to support, even nurture, new ways of } \\
\text { teaching tomorrow's designers? }\end{array}$
\end{tabular}

Davies (2000)

How are we to modify existing art and design practice in the light of our concerns, incorporating best practice from other disciplines, without damaging what is already done well?

Hope (2000)

What will future students need for their toolkit, not just for survival but to ensure the ability to effectively work in and help push forward the whole area of Web design?

Staples (2001)

The digital has exploded our expectations, blurred our boundaries, and rendered obsolete what we thought we cared dearly about. What are now "the basics" in teaching and learning design?

Fried (2001)

How much will undergraduates need to know in order to become successful designers in an electronic environment, as opposed to print, environmental design, or any other graphic design specialty?

Dubberly (2001)

How to satisfy demand for courses that will prepare students for the Web design market, while also preparing students for a world that will change greatly over the next five years - and even more over the forty or fifty years a graduating student might expect to practice?

Stone (2004)

Given the constraints of structured curriculum, how do we integrate this rapidly emerging field [interactive multimedia] into design education appropriately?

McKnight (2004) And sure, a student might become a passable generalist, but cans/he be a skilled specialist in more than one field? In four years of less?

Warner (2005)

What can we do, not just in classroom pedagogy but also in curricular structure, to produce first-rate thinkers as well as exceptional designers?

Scholz (2005) What is the professional future of a student graduating from a newmedia arts program in the post-dotbomb era? What are innovative structures for new-media arts education?

Haley (2006)

Will it be possible for emerging students to specialise in one area of graphic design? Or will we have to learn how to specialise in several areas? Will the division between print and web designers remain, or cease to exist?

Egenhoefer (2007) How do you teach contemporary media and digital design when the amount of information students are coming in with is increasing faster than some faculty are learning it?

McArthur (2007) If design graduates need to be multidisciplinary in outlook and capability, cross-culturally literate and adaptive, facilitators and collaborators - then what does this mean for the way design education is delivered? What are the skills design graduates need in the global environment?

Barnes-Powell (2008) Can we meet the challenges of the $21^{\text {st }}$ Century holding on to the educational ideologies of the $19^{\text {th }}$ Century? 
Higgins (2008)

Steane (2010)

Dubberly (2011)

Min (2011)

Poggenpohl (2012)
Should design students specialise in one design discipline? Is it more important for design students to graduate with a deep understanding in a specialised aspect of design, or with a broader, shallower knowledge of all aspects of the design field?

In a world of growing complexity, what is the right thing to teach?

In fact, the best young designers are teaching themselves to code, and the best young engineers are teaching themselves to design. Is this a race? Or will they converge? Can we create schools for hybridity?

How can we prepare our students to meet today's challenges in the global economy, ever changing technologies and complex social and political conditions?

Many educators are aware of the need for change, but the variety and interconnectedness of its aspects are confounding. Where to start - what is most essential - these are fundamental questions, and, if addressed, how do we know they are improvements?

It is evident from Table 1 that the emergence of digital media and its inherent increasing complexity has created many challenges for design education. It is also interesting that over a period of a decade and a half, similar questions have been asked which reflect the broadening scope of the design discipline, the appropriate skill set for a design graduate to possess in order to respond to future trends, the place of technology within the curriculum, and how a design curriculum should be structured.

Nevertheless, there is a slight shift of focus noticeable in the questions. During the time when digital media and especially the Internet were "new" in Western societies (approximately 19952002), the "computer" and "digital media" were identified as distinct challenges to master. In recent years, however, debate has developed around a much wider context than just managing learning and teaching with digital tools. The questions emerging after 2004 indicate that a radical transformation or re-invention was necessary and hence focused more explicitly on new curriculum design and pedagogical approaches which would equip the design graduate with adequate skills for an unpredictable future. Most recently, in addition to acknowledging that change is required, the request for systematic evaluation of any new programs (acknowledging the lack of published systematic research in this area) is gradually emerging (e.g. Poggenpohl, 2012).

\section{The big squeeze in design education}

The rapidness with which digital media emerged during the mid-1990s was in fact "severely challenging educators to respond and to incorporate these new dimensions into graphic design curricula" (McCoy, 1998b, p. 11). New subject areas such as Web design or interactive multimedia design needed to be introduced leading to what Justice (1998) described as the "big squeeze." Justice argued that the traditional design curriculum had been squeezed in order to "add the new technologies that students learn during their design education" (p. 53). Heller (2001), Wands (2001) and Sevak (2005) have shared this view more recently and Heller explained that "graphic design and computer courses must today be augmented by animation, film, sound, even script writing" (p. x) which all need to "fit in" the design curriculum. Figure 1 provides a schematic view of the add-on approach that many design programs have followed to incorporate this growth in digital media (Fried, 2001; Heller, 2005b). 


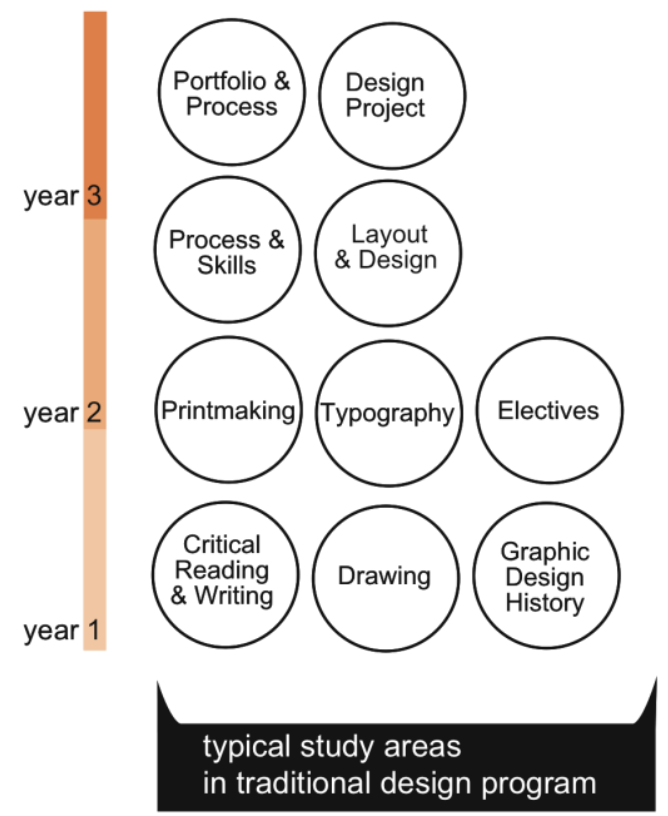

Figure 1. Expansion of traditional design programs through introduction of digital media subjects.

The strategy of adding subject areas to the curriculum as a first response to the emergence of digital media, however, is ongoing. For example, Davis (2011) argued that "in recent decades, design schools have added content to full programs of study in a curriculum-by-accrual attempt to respond to new practices and technologies" (p. 74). As exemplified in Figure 1, the "squeeze" certainly challenges educators and students in that more needs to be taught and learned within the program of study. Heller (2005a) is highly critical of this approach arguing that "any individuals or institutions that claim to impart total mastery of graphic design (with all it multidisciplinary complexities) in less than four years are kidding themselves and everyone else" (p. ix). Lehrer (2005) also criticised this approach saying that in his view "a more expansive approach ... can foster dilettantism" (p. 80). McKnight (2004) added that this kind of "hybrid education tries to cram so much into so little time that nuances are often lost. What students gain in formal skills may be lost in theory, history, writing, and finesse" (para. 5). In the ever-broadening design industry, which continues to evolve and shift, Higgins (2008) argued that the challenge persists in that the "single largest issue of undergraduate design programs is that there simply is not enough time to teach everything necessary for students to graduate with the knowledge and skills of a well-rounded designer" (p. 3).

\section{Interactive digital media technology, a blessing or a curse?}

For design students and design educators, learning and teaching in an ever-changing digital media environment can be demanding. The extensive use of hard- and software in digital media design and the time it takes to acquire technical skills (Heller, 2005b) is one challenge for students and educators to master. Another presents itself through information technology (scripting and programming), a component of most interactive digital media design projects such as websites, games or mobile device applications. While Reed and Davies (2006) explained that authoring software such as Dreamweaver ${ }^{\circledR}$ allowed "designers to move directly from a mocked-up design to a finished and coded layout with only a rudimentary understanding of the underlying code" when creating websites, the reality is that the "rapid deployment and development of dynamic online content ... has brought coding back into the design classroom" (Reed \& Davies, 2006, p. 183). Amiri (2011) confirmed this view by explaining that interactivity has become so sophisticated that the "code-less approach to developing interactivity is no longer sufficient to meet the 
sophistication that people and the industry have come to expect”' (p. 201).

As a consequence, design students can be overwhelmed with the amount and extent of the technical and technological skills they have to comprehend before they are able to start designing (Maeda, 2002). Initially having to learn and master a variety of software programs, video and sound compression technologies, as well as programming and scripting (for example, HTML/CSS, PHP, Java Script and Action Script) before engaging in the creative idea-finding process can limit their creative potential. This is especially the case given that "design students predominantly see themselves as visually and creatively minded people rather than 'scientifically' minded" (Amiri, 2011, p. 201). Although some authors, for example, Maeda (2002) and Amiri (2011), argued that design schools should provide ways by which students can learn both design and programming skills, others (e.g. Weinman 2001, Zee 2001) believe that an understanding is sufficient. Young (2001) saw the advantage for design students to understand information technology in enabling them to "work much more closely with the programming team members ... allow[ing] designers to communicate more intelligently and to have much closer collaborations" (p. 66).

Needless to say, design educators are usually similarly challenged by the intrinsic IT nature of interactive digital media (McCoy, 1998a). The dynamic and fast-changing nature of digital media presents many challenges; managing the increasing complexity of technology is only one of them. However, it is argued that radical change of existing design curricula is required to achieve a flexibility that allows the management of increasing complexity of technology in order to meet the demands of the persistently changing scope of the design profession.

\section{Radically challenging existing digital media design curricula to manage the increasing complexity of technology}

While many design degree programs followed the expansion approach illustrated in Figure 1 as a first reaction to the emergence of digital media, other strategies have also been developed. Because interactive media design often "lies at the juncture between arts/humanities and science/engineering" or at the "intersections of information technology and creative practices" (Mitchell, cited in Amiri, 2011, p. 201), some programs have tried to link design with information technology (e.g. Blahnik, Mc Vey \& Pankratz, 2006; Özcan \& Akarun, 2002; Scott \& Docherty, 2010). The majority of these alternative approaches were based around joint offerings, merging design and information technology (IT) in one course of study arguably driven by the symbiotic relationship the two disciplines display in the digital media market. Yet this approach has not necessarily decreased the number of knowledge areas to be mastered by a student. On the contrary, both areas (digital media design and IT) have continued in their own rapid development; therefore, the knowledge areas that need to be taught have increased. In addition, in terms of the outcome of these types of programs, Scott and Ursyn (2006) argued that students undertaking such degrees tend to be better in either design or in IT.

The digital media design industry has taken a different approach and has switched to multidisciplinary collaborative teamwork as a response to the increasing complexity of technology and changing nature of projects (Friedman, 2000; Kerlow, 2001; Niederhelman, 2001; Sommese, 2007; Whyte \& Bessant, 2007). This approach was not automatically anticipated by higher digital media design education (Design Council and Creative \& Cultural Skills, 2007; Niederhelman, 2001; Szenasy, 2004; Triggs, 2002). There is a limited body of literature that explores the use of, and potential for, collaborative multidisciplinary approaches to design education at the undergraduate level. Nevertheless, some institutions have trialled multidisciplinary approaches to interactive media design education involving collaborations between creative arts students such as visual communication, design, visual arts, fine arts or art students and computer science students (e.g. Dickey, 2010; Duesing \& Hodgins, 2004; Ebert and Bailey, 2000; McDonald \& Wolfe, 2008; Stone, 2004). Aiming to mirror industry practice, cross-disciplinary production teams are established according to the "nature of the task" (McCormick, 2004) and as found in the industry when producing games or animations (Ebert \& Bailey, 2000; McDonald \& Wolfe, 2008). When comparing various examples, educators see similar benefits for students who participate in 
multidisciplinary collaboration such as: enhanced generic skills including communication, teamwork and negotiation skills, appreciation for other disciplines, and a better understanding of the collaborative process as it is applied in industry. Stone (2004) also saw these benefits but, in addition, urged educators to have meaningful collaborations, offering that, "as educators, I believe we must extend ourselves beyond the confines of our individual disciplines to develop pedagogy that addresses the unique characteristics of interactive multimedia. I propose an interdisciplinary convergence to achieve this" (para. 4). Stone (2004) suggested an example of how this might work in practice: "design problems centered on hand-held product interfaces, environmental kiosks, automobile instrumentation, or systems applications may ... propose team teaching situations with colleagues in companion disciplines such as HCI, industrial design, interior space design, or cognitive engineering" (para. 25).

\section{The social media explosion - further revolutionary change at our doorstep?}

While digital technology continues to evolve, advancements - particularly in Internet technology embodied through Web 2.0 technologies - have yet again brought about unprecedented change in people's personal and professional lives (Benioff, 2012; Caper, 2013). Web 2.0 technologies allow the Internet user greater participation in creating and managing content. Users have a voice and the voice is heard by anyone who has access to the Internet. Applications, known as social media software or simply social media, have rapidly been embraced by the public although more quickly by the younger generation (Hurn, 2012). This is thought to be because they "have provided Internet users with the ability to easily create, contribute, communicate, and collaborate in the online environment without [the] need for specialized programming knowledge" (LeNoue, Hall \& Eighmy, 2011, p. 5). Web 2.0 technologies have created a responsive World Wide Web. Early applications included key elements such as "Really Simple Syndication (RSS) to rapidly disseminate awareness of new information; blogs to describe new trends; wikis to share knowledge; and podcasts to make information available 'on the move"' (McLean, Richards \& Wardman, 2007, para. 1). Social networking services such as Facebook and LinkedIn and also media sharing sites such as Flickr (2004), YouTube (2005), Pinterest (2010) and Instagram (2010) have gained unprecedented user engagement. Instagram, for example, has some 90 million monthly active users who upload 40 million photos daily and add 1000 comments about their photos (DesMarais, 2013).

Social media are seen by some as "revolutionary" (Caper, 2013; LeNoue, Hall \& Eighmy, 2011) because people "now use social technology to help shape the world's events and culture" (Benioff, 2012); others see social media as part of incremental innovation (Strauss, 2013). This is not to say that the popularity of social media has had no effect on the design profession and subsequently on design education. This is because social media are user-generated media and "collaborative cocreation is one of the main way forming information in the social network" (Wikipedia, 2013a, para. 35). Platforms such as 99designs.com (a leading marketplace for graphic design, including logo design, web design and other design contests) or crowdSpring.com (a leading marketplace for custom logo design, web design, graphic design, industrial design and writing services) tap into the creative domains of designers and change how business is conducted. The new "social media tools, which place creation, publication and critique in the hands of web users, have been recognised as having a role in democratising creativity, making the means of production and distribution accessible to most of the developed world" (Allen, Caple, Coleman \& Nguyen, 2012). This " ccloud' design world" has according to Perryzucker (2009), "reduced the designer-client relationship to a few mouse clicks" (para. 4).

Such democratisation of design certainly has its critics. They question, amongst other things, the quality of work created by amateurs who penetrate the design market (Howe, 2009; Perryzucker, 2009) causing "the blurring of the boundaries between amateur and professional design practice" (Massanari, 2012, para. 45). This echoes similar concern from the time when people were selfeducated web designers who "received their education from software manuals and Photoshop ${ }^{\circledR}$ filters" to conquer the new domain (Nowacek, 2001, p. 189). Advocates see the advantage in co- 
creation or the user-centred design participation process and welcome the "'open-source' dialogue that invites the audience into the creative process" (Duffy \& Partners, 2008, para. 8), a trend that has recently grown in popularity. In particular, it has been evident in the social and public innovation sector where user participatory design approaches are increasingly utilised to humanise services. Either way, social media are currently still considered in their infancy (Caper, 2013) and it remains to be seen whether design education must substantially change its content, methods or the processes taught. It is useful at this point to consider the question if we will "need to educate a new generation of designers to both embrace crowdsourcing and its outcomes on products, services and experiences? And is that enough?" (Russo, 2009, para. 14). The full impact of social media on design education is yet to be determined but can currently be considered as marginal, in particular when compared to the impact the emergence of digital media has had. That is, there appears to be no urgent need to change "what" we teach; yet there are suggestions to rethink "how" we teach.

\section{Social media in design education - technology with potential?}

Social media and its quick uptake amongst higher education students (Tate \& Osborne, 2013) have impacted on education because "social software applications are driving new paradigms in digitally mediated education delivery" (LeNoue, Hall \& Eighmy, 2011, p. 9). This new area of engagement (with its opportunities and also challenges) is not limited to design education but influences educators in all disciplines (and also on all levels from kindergarten to higher education). This broader impact and the fact that "social media [offer] educators more ways to engage learners than any preceding educational technology" (LeNoue, Hall \& Eighmy, 2011, p. 4) appears to drive change on an institutional level faster than ever before. Social media tools that have been on the market longer, such as blogs (which became increasingly mainstream in early 2000s (Wikipedia, 2013b)), are often already integrated in Learning Management Systems (LMS) such as Blackboard which are used in many universities today (Park, 2011). An emerging advantage of social media is the underlying principles of how social media works which suggest a particular potential for design education, especially the design studio.

Digital technology has introduced computer labs as a new central learning space for design students. As a result, studio-based learning in its traditional sense appears to be in decline in higher education institutions (Ellmers, 2005; STP, 2010). This is despite the fact that characteristics of the studio have been identified as supporting interaction, active learning and social engagement (Carbone, Lynch, Arnott \& Jamieson, 2000; Sara, 2006; Shreeves, 2011). These however, are also characteristics connected to the use of social media tools (LeNoue, Hall \& Eighmy, 2011; Russo, Mah, Marshal \& Payson, 2007). Could these services be utilised to revitalise studio-culture in a contemporary sense? And how can these technologies be used to facilitate social interactions, which were inherent to traditional studio culture, between teachers and students, and between students themselves?

Tate and Osborne (2013) have recently conducted a study which explored "whether or not Facebook could be used to increase the social interactions within an architectural studio" (p. 11) which revealed that in their case a "sense of community was developed within the most successful online studio groups, with participation the key to the quality of social interaction in this medium" (p. 11). Coleman (cited in Allen, Caple, Coleman \& Nguyen, 2012) who used Facebook as social community space in the College of Fine Arts reports an "increased interaction between students and peers, students and lecturer, and students and tutors, which led to development of a learning community with shared resources" (p. 3).

Social media is relatively new but have become a major part of students' everyday lives with "the boundaries between online and 'real-world' communities ... rapidly stretching if not completely deteriorating" (Davis III, Deil-Amen, Rios-Aguilar \& Canché, 2012, p. 3). Clearly, more research is needed in how design education can take advantage of social media's potential to reconstruct a present-day design studio. 


\section{Facing the challenges: radical innovation in a Digital Media Design major}

The author teaches at a creative arts school at a medium-sized Australian University, where the Digital Media Design major is a sequence of eight subjects taught across a three-year undergraduate degree program titled Bachelor of New Media Arts (BNMA). The study program is intended to prepare students to work as digital media designers in both print and interactive media. In particular, the interactive media focus of the degree has created constant challenges for educators in guiding students to the completion of contemporary interactive media design projects. Teaching advanced information technology was outside the areas of expertise of design educators and projects could not always be developed to their full potential. Although employing tutors who were knowledgeable in, for example, $M y S Q L^{\circledR}$ data base programming or action scripting (a script language integrated in the interactive animation software Flash ${ }^{\circledR}$ that allows dynamic interaction and content creation) was considered, there was ultimately not enough time to teach design students interface and interaction design aspects while at the same time advancing them in the required IT content. As the interactive media design projects became more sophisticated and hence more complex, it became clear that, in a similar way to industry, the required expertise for creating today's increasingly sophisticated interactive media design projects rarely resides within one educator alone or within one student. The time for teaching static web page design by one design educator to design students or a team of design students is over. If the school wanted to keep up with technological change in the interactive media design industry and offer students relevant and up to date content, radical rethinking of the Digital Media Design program was required. A response that would allow managing the increasing complexity of technology in a flexible way was urgently needed.

\section{The POOL Model}

As a result - and starting in 2009 - multidisciplinary teamwork was implemented in three subjects in the Digital Media Design major: Introduction to Web Design, Interactive Media Design and Creative Exchange Project. The multidisciplinary framework known as the POOL Model (Fleischmann, 2010) facilitates the constellation of diverse disciplines in two pools - a teaching and a learning pool - to allow dynamic responses to problems according to their nature. Depending on the subject, up to eight disciplines can be available in both pools (e.g. digital media design, sound, photo media, IT, business). In two subjects, the symbiotic relationship between digital media design and IT is central to the multidisciplinary collaboration, with other disciplines such as multimedia journalism and business adding to the collaboration on specific projects. While much of the previous research has focused on the benefits and challenges experienced by digital media design students (e.g. Fleischmann; 2012; Fleischmann \& Daniel, 2013; Fleischmann \& Hutchison, 2012), a less well-documented side of the framework is how well it facilitates keeping abreast with the increasing complexity of technology and how educators benefit from it.

In the teaching pool, educators from diverse disciplines work collaboratively to define a problem or project and create a learning environment for students to solve the problem or develop the project in multidisciplinary teams. People external to the university are included as part of the teaching pool; industry professionals, community members as clients, advisors, experts or sponsors. Students work on real-world projects in two of the subjects. In the other, the $3^{\text {rd }}$ year subject Interactive Media Design, the projects are fictional to give students the scope for the development of idealistic or visionary ideas without real-world or commercial limitations. This subject is used here in this paper to illustrate how the increasing complexity of technology has been managed through the implementation of the POOL Model framework.

Design and IT educators as well as digital media design and IT students work collaboratively in the Interactive Media Design subject, allowing the content and project brief to evolve over time in response to technological change. To elaborate, prior to 2009, design students developed and designed static websites as teams of designers. In the first two years of the framework's implementation, digital media design and IT students were given the brief of developing an 
interactive multimedia media online shop. The IT and design educators delivered content to students accordingly; IT students learned to "integrate XML with Action Script...[and] figure out how to use PHP and connect to MySQL" (IT educator, 2009), and design students learned about interface, interaction design und user guidance in particular in regards to online shopping. The collaborative project outcomes were far more advanced compared with projects produced by design students only with the multidisciplinary collaborative projects displaying dynamic content and a higher level of interactivity. As the IT educator (2009) described it at the time: "projects were really beyond the scope of just IT or just design students." In its third iteration under the POOL Model framework (2011), the project brief was yet again changed to reflect the essential role and development of mobile technology and applications (apps).

Students were asked to create a mobile application for elderly people that makes growing old seem more attractive and inviting (see Fleischmann, Visini \& Daniel, 2012 for a detailed description). In addition to engaging both digital media design and IT students in researching, and engaging in an important and challenging problem of our society today, design students needed to learn about interface design for small screen devices and IT students needed to learn how to develop mobile apps. An additional IT tutor, a specialist, was involved for the development of mobile apps. In 2012, the project brief was developed to reflect the increased focus on responsive mobile apps and geolocation social networking apps in the real world market. Students were asked to develop and design a Traffic Incident Report System that makes use of modern technology incorporating social media software (e.g. mobile technology, web, geolocation, twitter, RSS feeds) and interconnect such technologies within the system (see AUC, 2012 for more specific project outcomes).

Overall, the project brief has become more sophisticated each year to reflect current technological developments in the digital media design industry. Having started with two educators (one design and one IT) in 2009, by 2012 four educators (two design and two IT educators) delivered the content for the Traffic Incident Report System, thus also reflecting the increased complexity and sophistication of the project and the diverse expertise needed. Figure 2 summarises the evolving nature of the Interactive Media Design subject. 

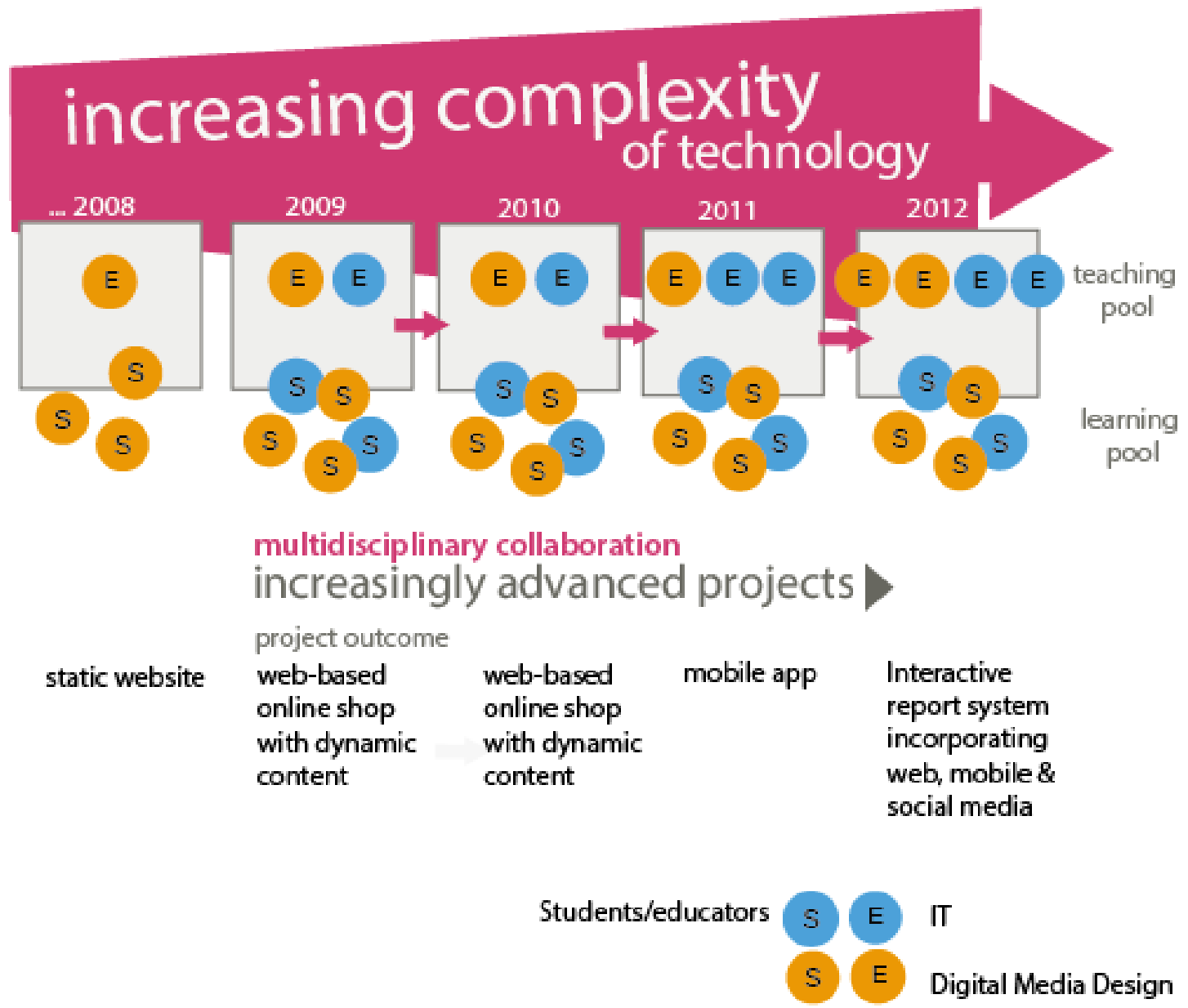

Figure 2. Managing the increasing complexity of technology through multidisciplinary collaboration: the evolving nature of a 3rd year Interactive Media Design subject.

While the projects or content delivered need not necessarily change every year, the pooling of multidisciplinary expertise in the teaching and learning pool makes allowance for educators to do so. That is, the availability of diverse expertise in educator and student teams makes it possible to embrace technological change and work collaboratively on contemporary interactive media design solutions.

Implementing the multidisciplinary collaborative POOL Model framework represented a radical change to the existing delivery of the design curriculum at the author's institution. While not without its challenges - the implementation depended on motivated educators being prepared to contribute their time and organisational skills, as well as willingness to move out of their comfort zone - the framework facilitates keeping abreast of technological advancements. All design and IT educators involved in the delivery of the subject between 2009 and 2012 agreed that projects could not have been developed by a single discipline; as one IT educator (2010) commented: "Design students didn't feel limited by their knowledge of the back-end stuff. ... the knowledge from those disciplines was shared in such a way that the solutions were possible and of higher quality." These educators also agreed that developing and continuing to change the project brief was only possible in and through collaboration with educators from the other discipline. An IT educator commented in 2010 that: "this was the second time I'd worked with the design lecturer, I think actually it worked pretty well. We clearly come from two different worlds but working together opens up so many possibilities ... it's a genuine collaborative effort." 
Media Design student reflections on the impact of the POOL Model framework on their project outcome was largely positive with $86 \%$ of students in $2009,94 \%$ in 2010 and $83 \%$ of students in 2011 stating that their project had benefitted through working in multidisciplinary teams (detailed student reflections on benefits and challenges can be found in Fleischmann \& Daniel, 2013). Overall, the POOL Model framework allowed students to learn about and engage in the creation of complex and contemporary interactive media design projects.

\section{Social media and design technology: incremental change in a Digital Media Design major}

The use of the Learning Management System Blackboard's social media tools in the Digital Media Design major of the BNMA degree in the author's institution can arguably be called a tradition. Since 2007, digital media design students have been required to contribute to discussion boards and make use of other collaborative tools of the Learning Management System (LMS) to communicate, share and critique ideas online. Students upload links to media sharing services, such as YouTube, onto the LMS and can view or download lecture recordings (podcasts) they might have missed or want to review. Extending these mediated social media experiences more recently, digital media design students now also learn how to build their virtual/digital identity and how to promote themselves in cyberspace by making use of social media tools such as the professional networking site LinkedIn. Embracing the rise of social media did not require a radical change to the design curriculum but an incremental adaption to changing (technological) realities.

Another incremental change in the Interactive Media Design subject occurred through recent developments in the digital publication market. The rapid development of mobile technology has made tablet devices increasingly popular with digital publications viewed and read on the device. Digital Media Design students in the third Interactive Media Design subject were required to produce a design documentation for the project each year. They were asked to produce the design documentation in a different format each year progressing from a static word document to an interactive digital publication to be viewed on an iPad which can include sound, video, interactivity and connectivity. Regardless of technology, digital media design students could apply their knowledge of layout, typography, colour, video and interactive media design. Likewise, the design educator was able to deliver workshops to convey the knowledge required for the production of a multimedia .pdf, an epub and an interactive digital publication. However, can these progressive developments in the use of technology be seen as revolutionary innovation?

According to Strauss (2013) "[a]n innovation is revolutionary if it so changes society that going back to the pre-innovation technology would be catastrophic. By this standard, many of our most recent innovations are incremental, not revolutionary" (para. 3). In the context of the Interactive Media Design subject, the design documentation could in fact still be produced as a static word document or pdf. Nevertheless, design students need to be prepared for the contemporary workplace and therefore design educators need to explore the potential of new emerging technology. Ongoing and incremental change is a characteristic of all education and the design educator of today is in constant self-education to provide for the regular adjustments needed to keep design education relevant today and in future.

\section{Conclusion}

Unquestionably, technological change has affected and continues to affect design education as much as it has affected the design professional and the way designers work. The rapid emergence of digital media (Internet and interactive media) brought about a massive extension to design's traditional body of knowledge. The sophistication of interactive digital media has grown so significantly that extensive knowledge in several areas, most notably in information technology, is often required for their design and production. Digital media design educators and students are clearly challenged by the enormous rate of this technological progress. While the need for a radical change in design education has been evident for many years, it is still not always acted upon. Responses emerge, more like pockets of innovation, from some institutions. 
In 2009, the Digital Media Design major of the Bachelor of New Media Arts degree at the author's institution was radically changed in that the educational space for design students and design educators was altered from individual to collaborative and multidisciplinary in three subjects. Pooling educators and students with diverse expertise such as digital media design, IT, business and other creative arts disciplines to teach and learn in multidisciplinary collaborative teams has been liberating and enabling. The multidisciplinary collaborative approach to digital media design education has been effective in facilitating dynamic and flexible responses to on-going technological change - for both students and educators.

It is interesting that technological change, such as social media, often coined a "revolution," has not, thus far, affected design education in the same way as the emergence of digital media. Social media, while no doubt revolutionary in the way they influence society, create, as yet, a less urgent need for a radical change in design education. Nevertheless, social media are incrementally finding their way into the design curriculum to augment the way we teach and students learn.

Considering the technological developments of the last two decades and how they have impacted on individuals living in post-industrial societies, it is difficult to predict how and with what speed the digital media design profession will continue to change. What is clear is that it will. There appears to be no definite answer or "one right way" to approach the education of digital media designers - this is also a reflection of today's complex world. What is evident is that finding a way to manage the increasing complexity of technology within the design curriculum is key to keeping design education relevant regardless of evolving technological advances.

\section{References}

Allen, B., Caple, H, Coleman, K., \& Nguyen, T. (2012). Creativity in practice: Social media in higher education. Paper presented at ASCILITE: Future Challenges-Sustainable Futures Conference, Wellington, New Zealand.

Amiri, F. (2011). Programming as design: The role of programming in interactive media curriculum in art and design. International Journal of Art and Design Education, 30(2), 200210.

AUC (Apple University Consortium). (2012). Crossing the pedagogical divide. Wheels for the Mind, (Spring 2012, 1st Digital edition), 14-17. Retrieved from https://itunes.apple.com/au/app/wheels-for-mind-spring-2012/id560926371?mt=8

Barnes-Powell, T. (2008). Can we meet the challenges of the 21st century holding on to the educational ideologies of the 19th century? Paper presented at the Centre for Learning and Teaching in Art \& Design (CLTAD), London.

Blahnik, J., McVey, B., \& Pankratz, D. (2006). Adding concentrations to the CS major: Our dean calls us 'innovative'. Proceedings of the 37th SIGCSE technical symposium on Computer science education SIGCSE '06, 191-194.

Benioff, M. (2012, May 10). Welcome to the social media revolution. BBC News, Business. Retrieved 2 June, 2013, from http://www.bbc.co.uk/news/business-18013662

Boyarski, D. (1998). Designing design education. SIGCHI Bulletin, 30(3), 7-10.

Caper, T. (2013, May 30). Why your social media revolution should come from the top. Retrieved from http://socialmediatoday.com/tomcaper/1492101/why-your-soc

Canniffe, B. J. (2011). Designing in and for communities: Breaking institutional barriers and engaging design students in meaningful and relevant projects. Iridescent, 2011(March). Retrieved from http://iridescent.icograda.org/2011/05/10/designing_in_and_for_communities_breaking_institu tional_barriers_and_engaging_design_students_in_meaningful_and_relevant_projects.php 
Chaurasia, S. (2013). Augmented reality in retail: A revolutionary next generation technology. Retrieved from http://ssrn.com/abstract=2230808

Davies, S. B. (2000). Educating the multimedia designer. In E. Dudley \& S. Mealing (Eds.), Becoming designers: Education \& influence (pp. 63-79). Exeter, UK: Intellect.

Davis, M. (1998). How high do we set the bar for design education. In S. Heller (Ed.), The Education of a Graphic Designer (pp. 25-30). New York: Allworth Press.

Davis, M. (2011). Relevance in a complex world. In A. G. Bennett \& O. Vulpinari (Eds.), ICOGRADA Design Education Manifesto (pp. 72-75). Taipei: International Council of Graphic Design Associations.

DesMarais, C. (2013, January 20). Facebook's Instagram says it has 90 million monthly active users. PC World, 2013. Retrieved from http://www.techhive.com/article/2025801/facebooksinstagram-says-it-has-90-million-monthly-active-users.html

Design Council and Creative \& Cultural Skills. (2007). High-level skills for higher value. Retrieved from http://www.designcouncil.org.uk/publications/high-level-skills-for-highervalue

Dickey, M.D. (2010). Jiselle and the royal jelly: Power, conflict and culture in an interdisciplinary game design course. International Journal of Art and Design Education, 29(2), 163-172.

Dubberly, H. (2001). The baseball projects: A step-by-step approach to introducing information architecture. In S. Heller (Ed.), The Education of an E-Designer (pp. 132-141). New York: Allworth Press.

Dubberly, H. (2011). Input for updating the Icograda Design Education Manifesto. In A. G. Bennett \& O. Vulpinari (Eds.), ICOGRADA Design Education Manifesto (pp. 76-81). Taipei: International Council of Graphic Design Associations.

Duesing, J., \& Hodgins, J.K. (2004). Team teaching animation art and technology. Paper presented at the SIGGRAPH '04 ACM Educators program, Los Angeles, CA. Retrieved from http://portal.acm.org/citation.cfm?id=1186112

Duffy \& Partners. (2008). Why the Democratization of design is a good thing -- really. AdWeek. Retrieved from http://www.duffypov.com/duffy-article/1505/why-the-democratization-ofdesign-is-a-good-thing-really

Ebert, D.S., \& Bailey, D. (2000). A collaborative and interdisciplinary computer animation course. ACM SIGGRAPH Computer Graphics, 34(3), 22-26.

Egenhoefer, R.B. (2007). The latest new media pedagogy: the medium or the message? Paper presented at the DEFSA Conference Cape Town, South Africa.

Farber, D. (2013). The next big thing in tech: Augmented reality. CNET News. Retrieved from http://news.cnet.com/8301-11386_3-57588128-76/the-next-bi

Fleischmann, K. (2010). The POOL Model: Foregrounding an alternative learning and teaching approach for digital media design in higher education. Art, Design and Communication in Higher Education, 9(1), 57-73.

Fleischmann, K. (2012). Industry-driven design education: How much should market/industry dictate pedagogy? In G. Muratovski (Ed.), agIdeas Research: Design for Business, Vol. 1. (pp. 76-95). Melbourne: agIdeas Press.

Fleischmann, K., \& Hutchison, C. (2012). Creative Exchange: An evolving model of multidisciplinary collaboration. Journal of Learning Design, 5(1), 23-31.

Fleischmann, K., Visini, G., \& Daniel, R. (2012). We want to add to their lives, not take away. In P. Rodgers (Ed.), Articulating Design Thinking (pp. 107-133). Faringdon, UK: Libri. 
Fleischmann, K., \& Daniel, R. (2013). Managing increasing complexity in undergraduate digital media design education - the impact and benefits of multidisciplinary collaboration. Design and Technology Education: an International Journal, 18(3), 35-47. Retrieved from http://ojs.lboro.ac.uk/ojs/index.php/DATE/article/view/1875

Flew, T, (2008). New media: An introduction (3rd ed.). South Melbourne, Australia: Oxford University Press.

Fried, G. (2001). The wrong horse? In S. Heller (Ed.), The Education of an E-Designer (pp. 1013). New York: Allworth Press.

Friedman, K. (2000). Design education in the university: Professional studies for the knowledge economy. Paper presented at the Re-inventing design education in the university, International Perth, School of Design, Curtin University of Technology.

Gromala, D. (2001). Learning the languages of Babel: An approach to new media pedagogy and the relevance of graphic design. In S. Heller (Ed.), The Education of an E-Designer (pp. 5056). New York: Allworth Press.

Haley, E. (2006). Give back, grow forward. Point - The AIGA Colorado Education Journal, Spring 2006, 16-19.

Heller, S. (2001). Introduction: Give me an E. In S. Heller (Ed.), The Education of an E-Designer. $1^{\text {st }}$ ed. (pp. vii-x). New York: Allworth Press.

Heller, S. (2005a). Introduction. In S. Heller (Ed.), The Education of a Graphic Designer. $2^{\text {nd }}$ ed. (pp. ix - xii). New York: Allworth Press.

Heller, S. (2005b). What this country needs is a good five-year design program. In S. Heller (Ed.), The Education of a Graphic Designer. $2^{\text {nd }}$ ed. (pp. 128-130). New York: Allworth Press.

Higgins, B. (2008). Program evaluation: Utilizing graduate and employer perception data in determining graduates' job preparedness levels. Journal of Industrial Technology, 24(3), 2-19.

Hope, M. (2000). What tangled webs we weave. In E. Dudley \& S. Mealing (Eds.), Becoming designers: Education \& influence (pp. 93-101). Exeter, UK: Intellect.

Howe, J. P. (2009, October 3). Is crowdsourcing evil? The design community weighs in. Wired. Retrieved from http://www.wired.com/business/2009/03/is-crowdsourcin/

Justice, L. (1998). The big squeeze. In S. Heller (Ed.), The Education of a Graphic Designer (pp. 53-55). New York: Allworth Press.

Lehrer, W. (2005). Emptying the spoon, enlarging the plate: Some thought on graphic design education. In S. Heller (Ed.), The Education of a Graphic Designer. $2^{\text {nd }}$ ed. (pp. 74-80). New York: Allworth Press.

LeNoue, M., Hall, T., \& Eighmy, M.A. (2011). Adult education and the social media revolution. Adult Learning, 22(4), 4-11. doi: 10.1177/104515951102200201.

Maeda, J. (2002, Summer). Design education in the post-digital age. Design Management Journal, 13(3), 39-48.

Massanari, A. (2012). DIY design: How crowdsourcing sites are challenging traditional design practice. First Monday, 17(10), 1 October 2012. Retrieved from http://firstmonday.org/ojs/index.php/fm/article/view/4171/3331

McArthur, I. (2007). Learning continuums: Emerging paradigms reflections on the impact of graduate design education on professional design practice in the $21 \mathrm{stC}$. visual: design: scholarship, 3(2), 26-38.

McCormick, R. (2004). Collaboration: The challenge of ICT. International Journal of Technology and Design Education, 14, 159-176. 
McCoy, K. (1998a). Introduction: Digital communications design in the second computer revolution. Retrieved 23 January, 2008, from http://www.highgrounddesign.com/mccoy/kmframe.htm

McCoy, K. (1998b). Education in an adolescent profession. In S. Heller (Ed.), The Education of a Graphic Designer (pp. 3-12). New York: Allworth Press.

McDonald, J., \& Wolfe, R. (2008). Using computer graphics to foster interdisciplinary collaboration in capstone courses. Paper presented at the CCSC: Midwestern Conference.

McEntaggart, P. (2010). Once upon a paradigm shift: Interactive storytelling in a new media context. Retrieved from http://www.inter-disciplinary.net/wpcontent/uploads/2010/02/patrickpaper.pdf

McKnight, J. (2004). Educating the hybrid designer. Retrieved from http://www.aiga.org/content.cfm/educating-the-hybrid-designer?pff=2

McLean, R., Richards, B.H, \& Wardman, J.I. (2011). The effect of Web 2.0 on the future of medical practice and education: Darwinian evolution or folksonomic revolution? Medical Journal of Australia, 187(3), 174-177.

McMillan, S. (2009). Don't call it a phone! Communication Arts: Illustration Annual, 51(3), 28-31.

Min, W. (2011). Design education manifesto. In A. G. Bennett \& O. Vulpinari (Eds.), ICOGRADA Design Education Manifesto (pp. 140-143). Taipei: International Council of Graphic Design Associations.

Niederhelman, M. (2001). Interactivity is not an elective. In S. Heller (Ed.), The Education of an E-Designer (pp. 14-19). New York: Allworth Press.

Norman, D. (2011). Design education: Brilliance without substance. core 77 - design magazine and resource. Retrieved from http://m.core77.com/blog/columns/design_education_brilliance_without_substance_20364.asp.

Nowacek, N. (2001). US versus them. In S. Heller (Ed.), The Education of an E-Designer (pp. 186-191). New York: Allworth Press.

Özcan, Oguzhan, \& Akarun, Lale. (2002). Teaching interactive media design. International Journal of Technology and Design Education, 19, 161-171.

Panning, S. (2005). The status of print designers and the influence of digital technology. Unpublished Master of Education thesis. Graduate College of Bowling Green State University. Retrieved from https://etd.ohiolink.edu/ap:10:0::NO:10:P10_ETD_SUBID:48332

Perryzucker, A. (2009). Democratizing Design? FAST COMPANY: Business + Innovation. Retrieved from http://www.fastcompany.com/1158036/democratizing-design

Poggenpohl, S. (2012). Envisioning a future design education: An introduction. Visible Language, 46(1/2), 8-19.

Reed, D., \& Davies, J. (2006). The convergence of computer programming and graphic design. Journal of Computing Sciences in Colleges, 21(3), 179-187.

Rubbo, A., Brew, A., \& Sachs, J. (2007). www.theglobalstudio.com: Towards a new design education paradigm? Retrieved from http://ses.library.usyd.edu.au/bitstream/2123/2130/1/TransUniRubbo17.pdf

Russo, A. (2009). Is crowdsourcing killing the traditional design industry? Retrieved from http://anthillonline.com/is-crowdsourcing-killing-the-traditional-design-industry/

Scholz, T. (2005). New-media art education and its discontents. art journal(Spring), 95-108.

Scott, A., \& Docherty, M. (2010). Experiments with design education in it - A longitudinal study. Paper presented at the CONNECTED 2010 - 2nd International Conference on Design Education, Sydney. 
Scott, T., \& Ursyn, A. (2006). A web design course team taught by professors in art and computer science. Journal of Computing Sciences in Colleges, 22(1), 205-210.

Sevak, P. C. (2005). Moving forward: Graphic design teaching and technology. Paper presented at the MX Design Conference 2005, Mexico. Retrieved from www.dis.uia.mx/conference/HTMsPDFs/GDTeachingandTechnology.pdf

Sommese, L. (2007). Graphic design curricula: Another reconsideration. Novum, 10(37), 12-17.

Staples, L. (2001). The new design basics. In S. Heller (Ed.), The Education of an E-Designer (pp. 6-9). New York: Allworth Press.

Steane, J. (2010). New communication design: New models, agendas, strategies? Paper presented at the CONNECTED 2010 - 2nd International Conference on Design Education, Sydney.

Stone, R. B. (2004). Thinking about design blurring boundaries: Interactive multimedia and interdisciplinary convergence. Retrieved from http://aim.johnkeston.com/abstracts/blurringboundaries/

STP (Studio Teaching Project) (2010). Studio teaching project. Retrieved from http://www.studioteaching.org/?page=key_findings

Szenasy, S. (2004). School survey 2004 - Do America’s design schools encourage interdisciplinary collaboration? Metropolis (August/September), pp. 88-91.

Tate, D., \& Osborne, L. (2013). Facebook: A 24 hour studio environment for contemporary architectural education. Retrieved from http://eprints.qut.edu.au/59549

Triggs, T. (2002). Curricula of collaboration: educating postgraduate students for the workplace. Paper presented at the Centre for Learning and Teaching in Art \& Design (CLTAD), London, April 10-12.

Wands, B. (2001). A philosophical approach and educational options for the e-designer. In S. Heller (Ed.), The Education of an E-Designer (pp. 20-23). New York: Allworth Press.

Warner, D. (2005). Cramming conceptual abilities into design curricula. Retrieved from http://www.aiga.org/content.cfm/cramming-conceptual-abilities-into-design-curricula?pff=2

Weiman, L. (2001). Education of a digital designer. In S. Heller (Ed.), The Education of an EDesigner (pp. 60-62). New York: Allworth Press.

Wikipedia. (2013a). Social media. Retrieved from http://en.wikipedia.org/wiki/Social_media.

Wikipedia. (2013b). History of blogging. Retrieved from http://en.wikipedia.org/wiki/History_of_blogging

Whyte, J., \& Bessant, J. (2007). Making the most of UK design excellence: Equipping UK designers to succeed in the global economy. Innovation Studies Centre, Tanaka Business School, Imperial College, London. Retrieved from http://johnbessant.net/uploads/books/32.pdf

Young, D. (2001). Why design students need to learn programming. In S. Heller (Ed.), The Education of an E-Designer (pp. 64-67). New York: Allworth Press.

Zee, N. (2001). The design technologist: Creating interactive experiences. In S. Heller (Ed.), The Education of an E-Designer (pp. 72-73). New York: Allworth Press. 